\title{
Xanthoradone $\mathrm{C}$, a new potentiator of imipenem activity against methicillin-resistant Staphylococcus aureus, produced by Penicillium radicum FKI-3765-2
}

\author{
Hiroyuki Yamazaki ${ }^{1}$, Satoshi Ōmura ${ }^{2}$ and Hiroshi Tomoda ${ }^{1}$
}

The Journal of Antibiotics (2010) 63, 329-330; doi:10.1038/ja.2010.40; published online 30 April 2010

Keywords: fungal metabolites; imipenem potentiator; methicillin-resistant Staphylococcus aureus (MRSA); Penicillium radicum; xanthoradone C

Xanthoradones A and B (Figure 1a) were isolated from the whole culture of Penicillium radicum FKI-3765-2 as potentiators of imipenem activity against methicillin-resistant Staphylococcus aureus (MRSA) $1^{1,2}$ Further precise analysis of metabolites in the whole culture led to the discovery of a new congener named xanthoradone $\mathrm{C}$ (Figure 1a). In this study, the isolation, structure elucidation and biological properties of xanthoradone $\mathrm{C}$ are described.

$P$. radicum FKI-3765-2 was fermented as reported previously. ${ }^{1,2}$ The 13-day-old whole culture $(1500 \mathrm{~g})$ was extracted with 3.01 of acetone. After the acetone extracts were filtered and concentrated to remove acetone, we extracted the aqueous solution with ethyl acetate. The extracts were dried over $\mathrm{Na}_{2} \mathrm{SO}_{4}$ and concentrated in vacuo to dryness to yield a red brown material $(2.5 \mathrm{~g})$. The material was dissolved in $30 \% \mathrm{CH}_{3} \mathrm{CN}$, applied to ODS column chromatography (150 g, SSC-ODS-7515-12; Senshu Scientific, Tokyo, Japan), and eluted stepwise with $30,50,70$ and $100 \% \mathrm{CH}_{3} \mathrm{CN}$ containing $0.050 \%$ TFA $(400 \mathrm{ml} \times 2$ tubes for each solvent). The second tube of $70 \% \mathrm{CH}_{3} \mathrm{CN}$ containing xanthoradones $\mathrm{A}$ to $\mathrm{C}$ was concentrated in vacuo to dryness to give a red brown material. The material (224 mg) was finally purified by preparative HPLC (column, Pegasil ODS, $20 \times 250 \mathrm{~mm}$; Senshu Scientific; solvent, $65 \% \mathrm{CH}_{3} \mathrm{CN}$ containing $0.050 \%$ TFA; detection, UV at $210 \mathrm{~nm}$; flow rate, $8.0 \mathrm{ml} \mathrm{min}^{-1}$ ). Under these conditions, xanthoradones $\mathrm{A}$ to $\mathrm{C}$ were eluted as peaks with retention times of 29.2, 31.6 and $39.6 \mathrm{~min}$, respectively. The fractions were concentrated in vacuo to dryness to give pure xanthoradones A (13.7 mg), B (6.95 mg) and C (1.68 mg) as orange crystals.

Physicochemical properties of xanthoradone $\mathrm{C}$ are summarized in Table 1A. Xanthoradone C showed UV absorption maxima at 220, 282 and $360 \mathrm{~nm}$, dissimilar to xanthoradones A and B (218 and $263-267 \mathrm{~nm}) .^{2}$ IR absorption at 3424 and $1629-1679 \mathrm{~cm}^{-1}$ suggested the presence of hydroxy and carbonyl groups in the structure. a<smiles>COC1=CC(=O)c2c(cc(C)c(-c3c(O)cc4cc5cc(C)oc(=O)c5c(O)c4c3O)c2O)C1=O</smiles><smiles>[R]C1=CC(=O)c2c(cc([R])c(-c3c(OC)cc4cc5c(c(O)c4c3O)C(=O)O[C@H](C)C5)c2O)C1=O</smiles>

\begin{tabular}{clc}
\hline Xanthoradone & $\mathbf{R}_{1}$ & $\mathbf{R}_{2}$ \\
\hline $\mathbf{A}$ & $-\mathrm{OCH}_{3}$ & $-\mathrm{CH}_{3}$ \\
B & $-\mathrm{CH}_{3}$ & $-\mathrm{OCH}_{3}$ \\
\hline
\end{tabular}

b

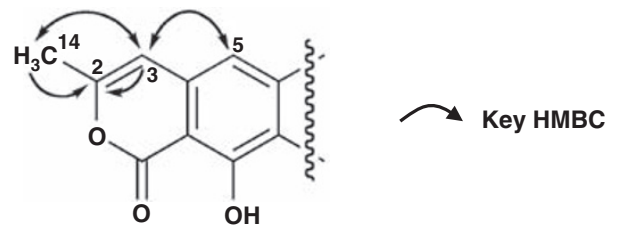

Figure 1 (a) Structures of xanthoradones $A$ to $C$. (b) ${ }^{13} \mathrm{C}^{-1} \mathrm{H} \quad \mathrm{HMBC}$ experiments of xanthoradone $\mathrm{C}$.

The molecular formula was determined to be $\mathrm{C}_{27} \mathrm{H}_{20} \mathrm{O}_{9}$ on the basis of HRESI-TOF-MS measurement, indicating that xanthoradone $\mathrm{C}$ was smaller by two hydrogen atoms than xanthoradone $A{ }^{2}$ The ${ }^{13} \mathrm{C}$ NMR

\footnotetext{
${ }^{1}$ Graduate School of Pharmaceutical Sciences, Kitasato University, Minato-ku, Tokyo, Japan and ${ }^{2}$ Kitasato Institute for Life Sciences, Kitasato University, Minato-ku, Tokyo, Japan Correspondence: Professor H Tomoda, Graduate School of Pharmaceutical Sciences, Kitasato University, 5-9-1 Shirokane, Minato-ku, Tokyo 108-8641, Japan. E-mail: tomodah@pharm.kitasato-u.ac.jp

Received 1 March 2010; accepted 2 April 2010; published online 30 April 2010
} 
Table 1 (A) Physicochemical properties and (B) ${ }^{1} \mathrm{H}$ and ${ }^{13} \mathrm{C}$ NMR chemical shifts of xanthoradone $\mathrm{C}$

\begin{tabular}{|c|c|c|}
\hline & \multicolumn{2}{|c|}{ Xanthoradone C } \\
\hline \multicolumn{3}{|l|}{$(A)$} \\
\hline Appearance & \multicolumn{2}{|c|}{ Orange crystal } \\
\hline Molecular weight & \multicolumn{2}{|l|}{488} \\
\hline Molecular formula & \multicolumn{2}{|c|}{$\mathrm{C}_{27} \mathrm{H}_{20} \mathrm{O}_{9}$} \\
\hline \multicolumn{3}{|l|}{ HRESI-TOF-MS (m/z) } \\
\hline Calcd.: & \multicolumn{2}{|c|}{$487.1029(\mathrm{M}-\mathrm{H})^{-}$} \\
\hline Found: & \multicolumn{2}{|c|}{$487.1040(\mathrm{M}-\mathrm{H})^{-}$} \\
\hline $\mathrm{UV}(\mathrm{MeOH}) \lambda_{\max } \mathrm{nm}(\varepsilon)$ & \multicolumn{2}{|c|}{220 (10 800), 282 (22 500), 360 (3500) } \\
\hline$[\alpha]_{D}^{26}$ & \multicolumn{2}{|c|}{$+264.4^{\circ}\left(c=0.1, \mathrm{CHCl}_{3}\right)$} \\
\hline \multirow[t]{2}{*}{$\mathrm{IR}(\mathrm{KBr}) v_{\max }\left(\mathrm{cm}^{-1}\right)$} & 3424 & \\
\hline & \multicolumn{2}{|c|}{ Xanthoradone C } \\
\hline Position & $\delta_{c}$ & $\delta_{H}$ \\
\hline \multicolumn{3}{|l|}{ (B) } \\
\hline 1 & 177.8 & - \\
\hline 2 & 152.9 & - \\
\hline 3 & 104.6 & $6.28 \mathrm{~s}$ \\
\hline 4 & 132.4 & - \\
\hline 5 & 112.4 & $7.07 \mathrm{~s}$ \\
\hline 6 & 141.3 & - \\
\hline 7 & 97.9 & $6.76 \mathrm{~s}$ \\
\hline 8 & 160.6 & - \\
\hline 9 & 109.0 & - \\
\hline 10 & 154.5 & - \\
\hline $10-\mathrm{OH}$ & & $9.68 \mathrm{~s}$ \\
\hline 11 & 108.4 & \\
\hline 12 & 162.2 & - \\
\hline $12-\mathrm{OH}$ & & $13.6 \mathrm{~s}$ \\
\hline 13 & 98.1 & - \\
\hline 14 & 19.4 & $2.29 \mathrm{~s}$ \\
\hline 15 & 56.0 & $3.86 \mathrm{~s}$ \\
\hline $1^{\prime}$ & 190.6 & - \\
\hline $2^{\prime}$ & 109.5 & $6.09 \mathrm{~s}$ \\
\hline $3^{\prime}$ & 160.7 & - \\
\hline $4^{\prime}$ & 179.8 & - \\
\hline $5^{\prime}$ & 129.9 & - \\
\hline $6^{\prime}$ & 121.3 & $7.67 \mathrm{~s}$ \\
\hline $7^{\prime}$ & 147.3 & - \\
\hline $8^{\prime}$ & 132.1 & - \\
\hline $9^{\prime}$ & 159.7 & - \\
\hline $9^{\prime}-\mathrm{OH}$ & & $12.5 \mathrm{~s}$ \\
\hline $10^{\prime}$ & 112.0 & - \\
\hline $11^{\prime}$ & 56.6 & $3.92 \mathrm{~s}$ \\
\hline $12^{\prime}$ & 20.6 & $2.22 \mathrm{~s}$ \\
\hline
\end{tabular}

spectrum (in $\mathrm{CDCl}_{3}$ ) showed 27 resolved signals, which were classified into two methyl carbons, five $s p^{2}$ methine carbons, two oxygenated methyl carbons, nine $s p^{2}$ quaternary carbons, six oxygenated $s p^{2}$ quaternary carbons and three carbonyl carbons by analysis of the
DEPT and HSQC spectra. The ${ }^{1} \mathrm{H}$ NMR spectrum (in $\mathrm{CDCl}_{3}$ ) showed 20 proton signals, nine of which were suggested to be three hydroxy protons $(\delta 9.68,12.5$ and 13.6$)$ and two oxygenated methyl protons ( $\delta 3.86$ and 3.92). These results supported the molecular formula. The connectivity of proton and carbon atoms was established by the ${ }^{13} \mathrm{C}-{ }^{1} \mathrm{H}$ HSQC spectrum (Table 1B). Comparison of the ${ }^{1} \mathrm{H}$ NMR spectra between xanthoradones $\mathrm{A}$ and $\mathrm{C}$ indicated that they share the same skeleton; however, the $s p^{3}$ oxygenated methine proton $(\mathrm{H}-2, \delta$ 4.79) and the methylene protons $\left(\mathrm{H}_{2}-3, \delta 3.00,3.06\right)$ in xanthoradone A disappeared in xanthoradone $\mathrm{C}$, and the $s p^{2}$ methine proton ( $\delta$ 6.28) appeared in xanthoradone $C$. In addition, the methyl proton signal $\left(\mathrm{H}_{3}-15\right)$ changed to singlet from doublet and its chemical shift shifted to a lower field from $\delta 1.57$ to $\delta 2.29 .^{2}$ Accordingly, it was concluded that xanthoradone $\mathrm{C}$ is 2,3-didehydro-xanthoradone $\mathrm{A}$ (Figure 1a). In fact, cross peaks were observed from $\mathrm{H}-3(\delta 6.28)$ to C-2 $(\delta 152.8), \mathrm{C}-5(\delta 112.4)$ and C-14 $(\delta 19.4)$; from H-5 $(\delta$ 7.07) to $\mathrm{C}-3\left(\delta\right.$ 104.6) and from $\mathrm{H}_{3}-14(\delta 2.29)$ to $\mathrm{C}-2$ and $\mathrm{C}-3$ in the ${ }^{13} \mathrm{C}-{ }^{1} \mathrm{H}$ HMBC experiments (Figure $1 \mathrm{~b}$ ). The structure satisfied the degree of unsaturation, UV and the molecular formula.

Furthermore, xanthoradone $\mathrm{C}$ has a chiral axis in the structure. The configuration of the axis might be $M$ by comparing the CD spectra of $(P)$ - and $(M)$-vioxanthins; ${ }^{3}$ xanthoradone $\mathrm{C}$ show a negative cotton effect at $297 \mathrm{~nm}$ and a positive cotton effect at $278 \mathrm{~nm}$ as well as (M)-vioxanthin. ${ }^{3}$

Anti-MRSA activity of xanthoradone $\mathrm{C}$ was tested by the liquid microdilution method. ${ }^{4}$ Xanthoradone $\mathrm{C}$ showed weak anti-MRSA activity with an MIC value of $8.0 \mu \mathrm{g} \mathrm{ml}^{-1}$. Next, the potentiating effect of xanthoradone $\mathrm{C}$ on the activity of imipenem against MRSA was investigated according to the liquid microdilution method. ${ }^{1,4}$ The concentration of xanthoradone $\mathrm{C}$ was set at $2.0 \mu \mathrm{g} \mathrm{ml}^{-1}$ for this experiment, which showed no effect on the growth of the MRSA K-24 strain. ${ }^{1}$ Xanthoradone $\mathrm{C}$ showed moderate potentiating activity, reducing the MIC value of imipenem from 16 to $0.50 \mu \mathrm{g} \mathrm{ml}^{-1}$ (32folds), whereas xanthoradones $\mathrm{A}$ and $\mathrm{B}$ were reported to enhance imipenem activity 266- to 533-fold. ${ }^{1}$ Therefore, introduction of the double bond between $\mathrm{C}-2$ and $\mathrm{C}-3$ is unfavorable for the potentiation of imipenem activity against MRSA (Figure 1a).

\section{ACKNOWLEDGEMENTS}

This study was supported in part by the Sasakawa Scientific Research Grant (to HY) from The Japan Science Society. We express our thanks to Ms N Sato for measuring NMR experiments, Dr K Nagai and Ms A Nakagawa for measuring mass spectra, and Ms Erina Shimomura for excellent technical assistance.

1 Yamazaki, H., Nonaka, K., Masuma, R., Ōmura, S. \& Tomoda, H. Xanthoradones, new potentiators of imipenem activity against methicillin-resistant Staphylococcus aureus, produced by Penicillium radicum FKI-3765-2. I. Taxonomy, fermentation, isolation and biological properties. J. Antibiot. 62, 431-434 (2009).

2 Yamazaki, H., Ōmura, S. \& Tomoda, H. Xanthoradones, new potentiators of imipenem activity against methicillin-resistant Staphylococcus aureus, produced by Penicillium radicum FKI-3765-2. II. Structure elucidation. J. Antibiot. 62, 435-437 (2009).

3 Bode, S. E., Drochner, D. \& Muller, M. Synthesis, biosynthesis, and absolute configuration of vioxanthin. Angew. Chem. Int. Ed. Engl. 46, 5916-5920 (2007).

4 Committee for Antimicrobial Susceptibility Testing Method. Standard methods of Japanese Society of Chemotherapy. Chemotherapy 38, 102-105 (1990) (in Japanese). 